\title{
Efficacy of antibiotic therapy for peritoneal dialysis-associated peritonitis: a proportional meta-analysis
}

Pasqual Barretti*, João Vitor Pereira Doles, Douglas Gonçalves Pinotti and Regina El Dib

\begin{abstract}
Background: The choice of antimicrobials for initial treatment of peritoneal dialysis (PD)-related peritonitis is crucial for a favorable outcome. There is no consensus about the best therapy; few prospective controlled studies have been published, and the only published systematic reviews did not report superiority of any class of antimicrobials. The objective of this review was to analyze the results of PD peritonitis treatment in adult patients by employing a new methodology, the proportional meta-analysis.

Methods: A review of the literature was conducted. There was no language restriction. Studies were obtained from MEDLINE, EMBASE, and LILACS. The inclusion criteria were: (a) case series and RCTs with the number of reported patients in each study greater than five, (b) use of any antibiotic therapy for initial treatment (e.g., cefazolin plus gentamicin or vancomycin plus gentamicin), for Gram-positive (e.g., vancomycin or a first generation cephalosporin), or for Gram-negative rods (e.g., gentamicin, ceftazidime, and fluoroquinolone), (c) patients with PD-related peritonitis, and (d) studies specifying the rates of resolution. A proportional meta-analysis was performed on outcomes using a random-effects model, and the pooled resolution rates were calculated.
\end{abstract}

Results: A total of 64 studies (32 for initial treatment and negative culture, 28 reporting treatment for Gram-positive rods and 24 reporting treatment for Gram-negative rods) and 21 RCTs met all inclusion criteria (14 for initial treatment and negative culture, 8 reporting treatment for Gram-positive rods and 8 reporting treatment for Gram-negative rods). The pooled resolution rate of ceftazidime plus glycopeptide as initial treatment (pooled proportion $=86 \%[95 \% \mathrm{Cl}$ 0.82-0.89]) was significantly higher than first generation cephalosporin plus aminoglycosides (pooled proportion $=66 \%$ [95\% Cl 0.57-0.75]) and significantly higher than glycopeptides plus aminoglycosides (pooled proportion $=75 \%$ [95\% Cl 0.69-0.80]. Other comparisons of regimens used for either initial treatment, treatment for Gram-positive rods or Gram-negative rods did not show statistically significant differences.

Conclusion: We showed that the association of a glycopeptide plus ceftazidime is superior to other regimens for initial treatment of PD peritonitis. This result should be carefully analyzed and does not exclude the necessity of monitoring the local microbiologic profile in each dialysis center to choice the initial therapeutic protocol.

Keywords: Peritonitis, Peritoneal dialysis, Treatment, Meta-analysis

\footnotetext{
*Correspondence: pbarretti@uol.com.br

Botucatu Medical School, UNESP - Universidade Estadual Paulista, São Paulo,

Brazil
} 


\section{Background}

Although continuous peritoneal dialysis (PD) was introduced almost four decades ago, its application continues to be hindered by peritonitis, despite the large reduction of peritonitis incidence due to advances in connectology and widespread use of antibiotic prophylaxis. Peritonitis remains as a serious complication influencing patients' mortality, and is the most frequent cause of PD failure [1].

The choice of antimicrobial therapy for initial treatment is a crucial determinant for a favorable clinical course and outcome. Historically, this choice has been based on the recommendations of the International Society for Peritoneal Dialysis (ISPD), which has published six documents between 1989 and 2010 [2-7]. According to these guidelines, the initial treatment of peritonitis (prior to the results of microbiological tests) should be based on associations of drugs for coverage of Gram-positive cocci and Gramnegative bacilli. The recommendations about the class of antimicrobials have varied over time. In general, for coverage of Gram-positive cocci the use of a first generation cephalosporin or vancomycin has been proposed, while for Gram-negative bacilli an aminoglycoside or ceftazidime have been recommended. However, based on the available literature there is no consensus about the best antimicrobial therapy for the initial treatment of these infections, and few prospective and controlled studies have been published.

A systematic review with a meta-analysis of randomized controlled trials, published by Wiggins et al. [8], included 36 studies published between 1985 and 2006, and did not report superiority of any class of antimicrobials. One limitation of the study was the exclusion of a large number of publications with a high number of patients and episodes of peritonitis. Most of these excluded studies were case series. Thus, the present study aimed to analyze the clinical results of PD related peritonitis treatment reported in both, randomized controlled trials (RCTs) and case series studies employing an alternative methodology, the proportional meta-analysis, and to examine possible differences among therapeutic protocols.

\section{Methods}

\section{Literature search and studies selection}

A review of case series and RCTs containing the treatment of PD-related peritonitis was performed. There was no language restriction. Studies were obtained from the following sources: US National Library of Medicine (PUBMED; 1966-2013), Excerpta Medica database (EMBASE; 1980-2013) and Literatura Latino-Americana and Caribe em Ciências da Saúde (LILACS; 1982-2013). The last search date was $11^{\text {th }}$ January, 2013.

The databases were examined using a comprehensive search strategy for PD-related peritonitis and antibiotic therapy, along with $\mathrm{MeSH}$ and text words, including a list of synonyms (Appendix). The search strategy was adapted for each database in order to maximize the ability to identify eligible studies. The bibliographic references in relevant articles were also examined for eligible studies.

The following inclusion criteria were used: (a) RCTs and case series studies with a number of reported patients greater than five, (b) use of any antibiotic therapy, regardless of whether it was used for initial treatment (e.g., cefazolin plus gentamicin or vancomycin plus gentamicin), for Gram-positive rods (e.g., vancomycin or a first generation cephalosporin), or for Gram-negative rods (e.g., gentamicin, ceftazidime, and fluoroquinolone), (c) patients with PD-related peritonitis, and (d) studies specifying the rates of peritonitis resolution. The data from RCTs were incorporated in the analysis as discrete data sets. Studies in pediatric patients and those with incomplete data were excluded from the review.

Peritonitis diagnosis was based on at least two of the following: abdominal pain or cloudy dialysate, dialysate white cell count $>100 / \mu \mathrm{L}$ with at least $50 \%$ neutrophilic cells, and positive culture of dialysate [6,7]. We defined peritonitis resolution based on the following definitions used by authors of the included studies: disappearance of signs and symptoms within $96 \mathrm{~h}$ after the beginning of antibiotic therapy and a negative peritoneal fluid culture at least 28 days after treatment completion; an episode of peritonitis where the catheter remained in situ and symptoms and signs resolved; initial response to antibiotic therapy combined with no need to remove the PD catheter; complete resolution of peritonitis without relapse for 30 days following initial therapy completion; absence of symptoms of peritonitis and clear dialysate effluent 5 days after start of antibiotic therapy; sterilization of the dialysate with no relapse within 4 weeks after treatment; no relapse within 2 weeks after ceasing treatment; cure without altering either of the empirical antibiotics to second-line antibiotics; resolution of abdominal pain, clearing of dialysate, and dialysate neutrophil count less than $100 / \mu \mathrm{L}$ on day 10; complete resolution of peritonitis by antibiotics alone without relapse or recurrence within 4 weeks of completion of therapy; PD fluid became clear, patient survived the period of the treatment of peritonitis and 4 weeks after treatment ceased; PD catheter did not require removal to clear the infection, and no relapse of peritonitis caused by the same organism or with negative culture results within 4 weeks post treatment of the initial episode $[6,7]$.

\section{Data collection}

Two reviewers independently screened the titles identified by the literature search, extracted the data from the studies, and analyzed the results. Discrepancies in the results were resolved by discussion by the reviewers. A standard 
Table 1 Characteristics of case series and RCT studies including in the qualitative analysis, according to treatment target (initial, gram-positive and gram-negative rods) and the patient's renal basal disease

\begin{tabular}{|c|c|c|c|c|}
\hline Study & All studies & Initial treatment/Negative culture & Gram + & Gram - \\
\hline Total of studies (case series and RCTs) & 84 [15-98] & $\begin{array}{l}44[15-24,26,28,34 \\
40,55,57,60-87]\end{array}$ & $\begin{array}{l}36[15,18,20-25,29,30 \\
33-37,42,44,48,50,54 \\
55,57,63,75,77,85,86, \\
88-95]\end{array}$ & $\begin{array}{l}32[15,18,20,22,23,25, \\
31,32,35-37,39,41, \\
45-47,49,50,52,55,57, \\
63,69,77,78,86,91,93, \\
96-98]\end{array}$ \\
\hline No. of patients/No. of episodes & $9.268 / 16.109$ & $4.411 / 7.315$ & $3,526 / 6,259$ & 2,549/4,925 \\
\hline
\end{tabular}

\section{Basal renal disease}

Branchio-oto-renal syndrome

Chronic tubulointerstitial disease

Diabetes

Glomerulonephritis

Gouty

Hemolytic-uremic syndrome

Hypertension

IgA nephropathy

Interstitial nephritis

Systemic lupus

Malignancy

Multiple myeloma

Nephrosclerosis

Obstruction/Reflux

Others/unknown

Pyelonephritis

Policystic kidney disease

Renal artery stenosis

Renovascular

Systemic autoimmune disease

\section{Comorbidities}

AIDS

Cerebrovascular disease

Chronic lung disease

Connective tissue disorder

Congestive heart failure

Coronary heart disease

Current smoker

Dementia

Diabetes

Hemiplegia

Mild liver disease

Moderate or severe liver disease

Peptic ulcer disease

Peripheral vascular disease

Secondary hyperparathyroidism

Any Tumor, Leukemia, Lymphoma

$0 \quad 0$


Table 1 Characteristics of case series and RCT studies including in the qualitative analysis, according to treatment target (initial, gram-positive and gram-negative rods) and the patient's renal basal disease (Continued)

\begin{tabular}{|c|c|c|c|c|}
\hline CAPD & 50 & 32 & 24 & 23 \\
\hline APD & 11 & 7 & 7 & 7 \\
\hline Not reported & 37 & 9 & 11 & 9 \\
\hline Any change from APD to CAPD & NR & NR & NR & NR \\
\hline Mean age (years) & 57,36 & 55,65 & 58,44 & 56,53 \\
\hline
\end{tabular}

$\mathrm{NR}=$ not reported; $\mathrm{CAPD}=$ continuous ambulatory peritoneal dialysis; $\mathrm{APD}=$ automated peritoneal dialysis; $\mathrm{RCT}=$ randomized clinical trial.

form was used to extract the following information: authors and year of publication, country, number of participants and peritonitis episodes, patients' mean age, basal renal disease, comorbidities, PD modality (continuous ambulatory peritoneal dialysis [CAPD] or automated peritoneal dialysis [APD]), initial peritonitis treatment protocol and its adjustments, and outcomes.

We used the risk of bias approach for Cochrane Reviews to assess the RCT quality [9] as we are used to critical appraise RCT with this tool. Please, find below the reference. We have included one figure entitled Risk of bias summary: review authors' judgments about each risk of bias item for each RCT included.

\section{Statistical analysis}

The outcomes were treated as a dichotomous variable (peritonitis resolution versus no resolution) with respective 95\% confidence intervals (CI). Statistical heterogeneity was assessed with the $\mathrm{I}^{2}$ statistic, and significance was assumed when the $\mathrm{I}^{2}$ was greater than $50 \%$. The $\mathrm{I}^{2}$ statistic illustrates the percentage of the variability in effect estimates resulting from heterogeneity rather than sampling error $[10,11]$. Because of the clear differences among the included studies and several uncontrolled variables, we used a randomeffect model [12] to perform a proportional meta-analysis of case series studies $[13,14]$. The software used to plot the studies in the meta-analysis was StatsDirect.

For first generation cephalosporins, we included: cefazolin, cephalotin, cefamezin and cephaloridine. The only third generation cephalosporin we analyzed was ceftazidime. For aminoglycosides we included gentamicin, amikacin, netilmicin and tobramycin. Vancomycin and teicoplanin were considered in the analysis as glycopeptides. Finally, ciprofloxacin, levofloxacin and ofloxacin were the fluoroquinolones included.

A statistically significant difference between interventions was defined when their combined 95\% CIs did not overlap [13,14]. We considered $\mathrm{p}<0.05$ as statistically significant.

\section{Results}

The literature search was conducted through January 2013, and 6,743 titles had been identified. After the screening by title and abstract, we obtained full paper copies of 140 studies reporting antibiotic therapy for PD-related peritonitis that were eligible for inclusion. However, 56 of these studies were either cohort or off-topic. Hence, only a total of 64 case series studies (32 reporting initial treatment and negative culture, 28 reporting treatment for Gram-positive rods and 24 reporting treatment for Gram-negative rods) and 20 RCTs met all inclusion criteria (14 for initial treatment and negative culture, eight reporting treatment for Gram-positive rods and eight reporting treatment for Gram-negative rods). These studies included 9.268 patients with 16.109 episodes of peritonitis. A total of 4.411 patients (7.315 episodes) were reported for the initial treatment and negative culture, 3.526 patients (6.259) were reported for the Gram-positive group, and 2.549 (4.925) were reported for the Gram-negative group (Table 1).

However, from these total, 38 case series [15-52] were not included in the meta-analysis due to the lack of data. Methodological aspects of five RCT studies [53-57] had a risk of introducing bias, with inadequate blinding of participants, random sequence generation and incomplete outcome, and three RCTs was excluded from the quantitative analysis due to lack of data $[53,56,58]$. In this way, proportional meta-analysis was performed from 43 studies (Figure 1). We have summarized the risk of bias of RCT included studies in Figure 2.

\section{Comparisons for initial treatment or culture negative episodes}

Ceftazidme plus a glycopeptide as initial treatment was used in five studies [59-63] with 443 episodes; the pooled resolution rate was $86 \%$ (95\% CI $0.82-0.89)$. This resolution rate was significant higher than initial treatment with a first generation cephalosporin plus aminoglycosides (pooled proportion of $66 \%, 95 \%$ CI $0.57-0.75$ ) from 14 included studies [57,61,64-75] with 1,438 total episodes (Figure 3). Initial treatment with ceftazidime plus a glycopeptide also showed a higher resolution rate than a glycopeptide plus aminoglycosides (pooled proportion of $75 \%$, 95\% CI $0.69-$ 0.80 ) that were used in 16 included studies [55,66-68,75-86] with 574 episodes (Figure 4).

The following comparisons did not show statistically significant differences because their CIs overlapped: a first generation cephalosporin plus aminoglycosides (resolution rate $=66 \%, 95 \%$ CI $0.57-0.75$ ) versus glycopeptides plus 


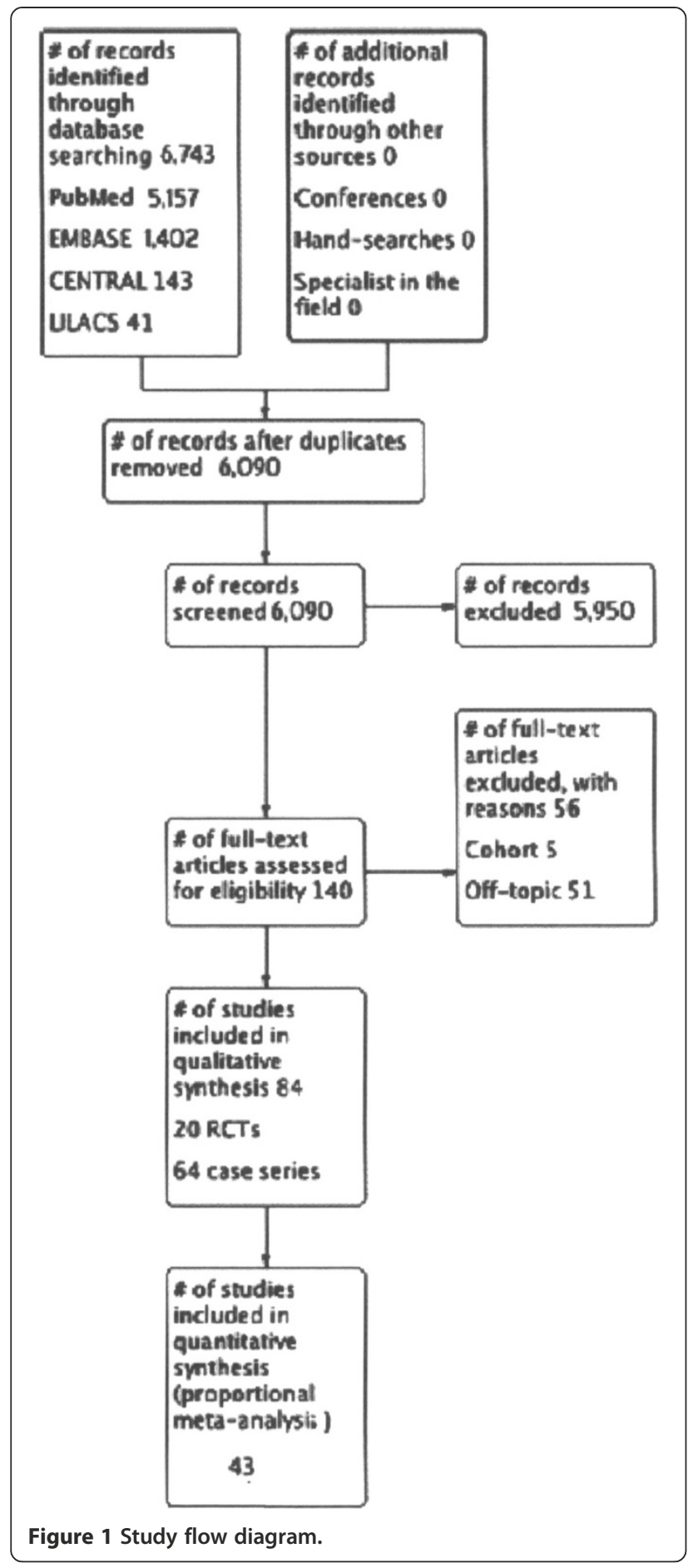

aminoglycosides (resolution rate $=75 \%, 95 \%$ CI $0.69-0.80$ ); a first generation cephalosporin plus aminoglycosides (resolution rate $=66 \%, 95 \%$ CI $0.57-0.75$ ) versus a first generation cephalosporin plus ceftazidime (resolution rate $=59 \%$, 95\% CI 0.32-0.83); glycopeptides plus aminoglycosides (resolution rate $=75 \%, 95 \%$ CI $0.69-0.80$ ) versus first generation cephalosporin plus ceftazidime (resolution rate $=59 \%, 95 \%$ CI $0.32-0.83$ ), and a first

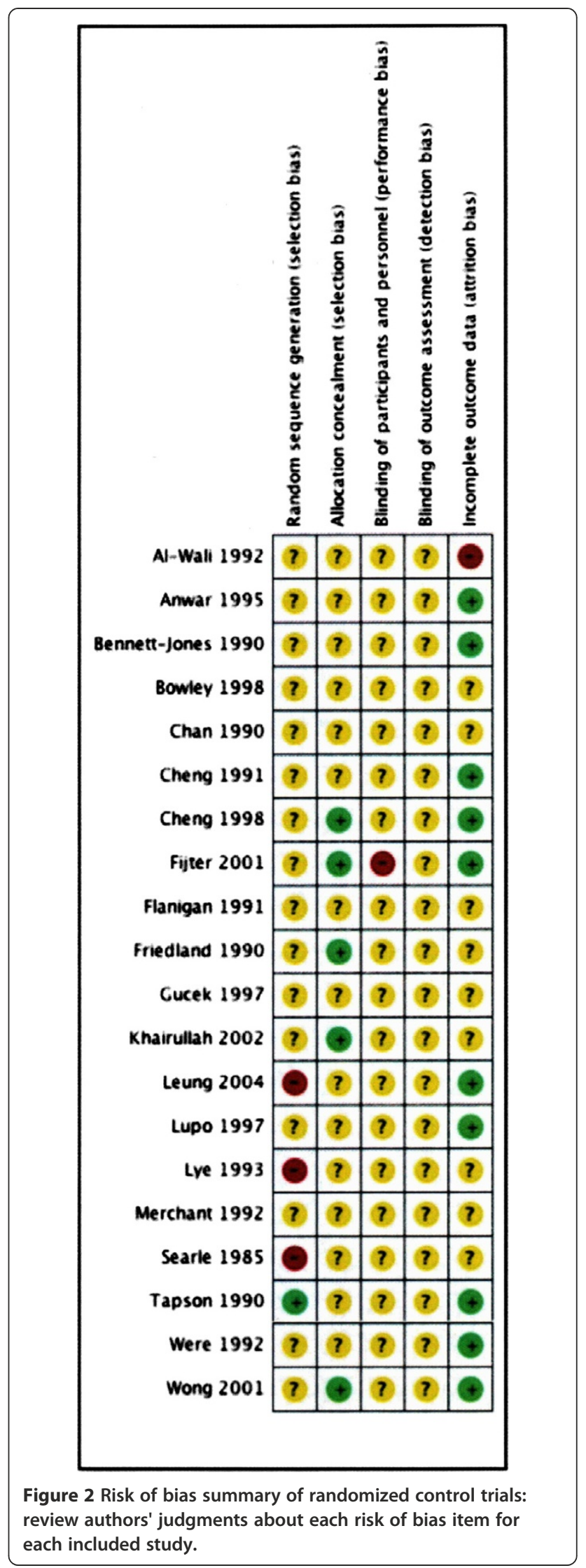




\section{Ceftazidime plus glycopeptide}

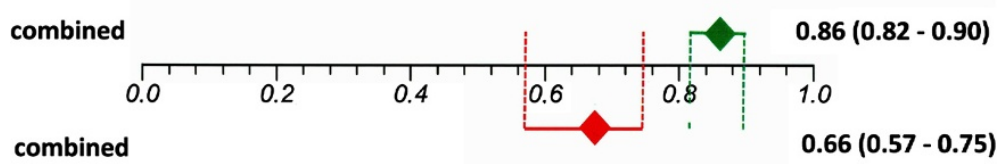

\section{First generation cephalosporin plus aminoglycoside}

Figure 3 Combined resolution rate with $95 \%$ Cls of studies of initial treatment with ceftazidime plus a glycopeptide versus a first generation cephalosporin plus an aminoglycoside.

generation cephalosporin plus ceftazidime (resolution rate $=59 \%$, 95\% CI 0.32-0.83) versus ceftazidime plus a glycopeptide (resolution rate $=86 \%, 95 \%$ CI $0.82-0.89$ ).

There was significant heterogeneity among studies for three of the initial treatment used (ceftazidme plus glycopeptide $\mathrm{I}^{2}=91.5 \%$; first generation cephalosporin plus third generation cephalosporin, $\mathrm{I}^{2}=94.8 \%$; third generation cephalosporin plus glycopeptide, $\mathrm{I}^{2}=8,02 \mathrm{E}-02 \%$.

\section{Comparisons for episodes due to gram-positive rods}

For treatment of episodes due to Gram-positive rods, the pooled resolution rate from 13 studies $[54,55,62,76,84,85,87-93]$ with 917 episodes was $78 \%$ (95\% CI 0.66-0.88) for a glycopeptide, while from five studies $[57,74,88,93,94]$ with 532 episodes for a first generation cephalosporin it was $73 \%(95 \%$ CI $0.55-0.88)$. There was no significant difference between the schemes.

There was significant heterogeneity among studies for both first generation cephalosporin and glycopeptide: $\mathrm{I}^{2}=94.6 \%$ and $94 \%$, respectively.

Comparisons for episodes due to gram-negative rods The pooled proportion resolution rate from nine studies [55,76,85,92,95-98] with 138 episodes was $68 \%$ (95\% CI
0.50-0.85) for a quinolone (Figure 5). For ceftazidime, the resolution rate was $61 \%(95 \%$ CI $0.53-0.70)$ from three studies $[68,56,98]$ with 117 episodes (Figure 6), and for aminoglycosides it was $65 \%$ (95\% CI $0.51-0.77$ ) from nine studies [55,57,62,68,76,85,90,97,98] with 211 episodes (Figure 7). There were no significant differences among the three drugs because their CIs overlapped.

There was significant heterogeneity among studies for both of the two drugs: $\mathrm{I}^{2}$ value was $79.3 \%$ for quinolone, and $71.1 \%$ for aminoglycosides.

\section{Discussion}

The choice of initial treatment of PD-related peritonitis remains a challenge to nephrologists who perform PD, particularly because of the absence of evidence to indicate superiority of particular recommended therapeutic protocols. Although the only available systematic review with meta-analysis of randomized clinical trials [8], and its recent update [99] did not show superiority of a specific class of antimicrobials a review of therapeutic protocols proposed by ISPD guidelines used in case series studies (which are typically excluded from meta-analyses) could potentially show differences in outcomes among antimicrobial regimens. In addition, the possibility of performing randomized clinical trials with a sufficient number of

\section{Ceftazidime plus glycopeptide}

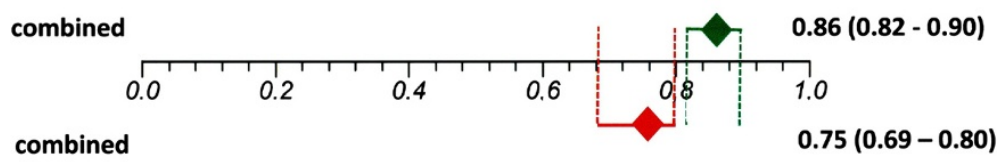

Glycopeptide plus aminoglycoside

Figure 4 Combined resolution rate with $95 \%$ Cls of studies of initial treatment with ceftazidime plus a glycopeptide compared to a glycopeptide plus an aminoglycoside. 


\section{Proportion meta-analysis plot [random effects]}

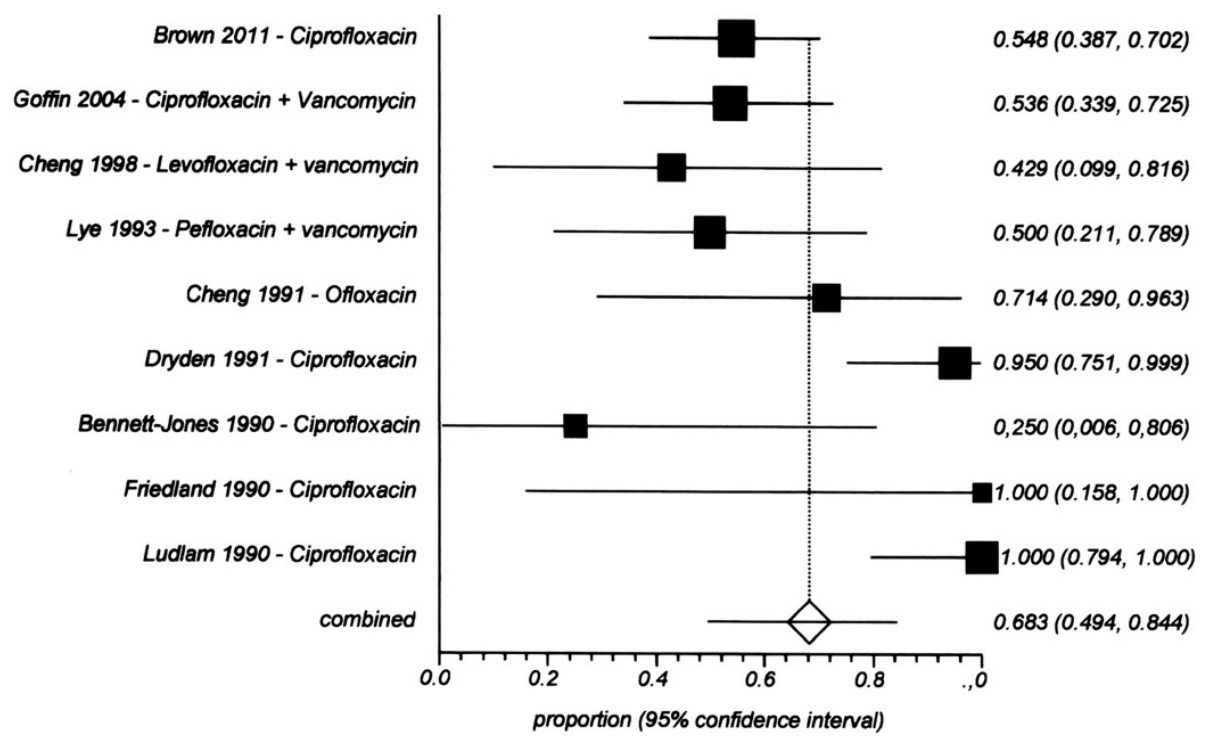

Figure 5 Proportional meta-analysis of studies of the resolution rate of quinolone treatment for gram-negative peritonitis.

patients has become more remote because of the current low incidence of PD-related peritonitis.

A narrative review of antimicrobial treatment of patients with PD-related peritonitis published in 1991 [100] concluded that the optimal empirical treatment was weekly vancomycin plus ceftazidime. Interestingly, the present study using proportional meta-analysis of case series was able to identify the superiority of the combination of glycopeptides plus ceftazidime in the initial treatment of PDrelated peritonitis, when compared with a glycopeptide plus an aminoglycoside and when compared with a first generation cephalosporin plus aminoglycosides. This result strongly suggests that the differences found may be related to a better coverage of Gram-negative bacilli of

\section{Proportion meta-analysis plot [random effects]}

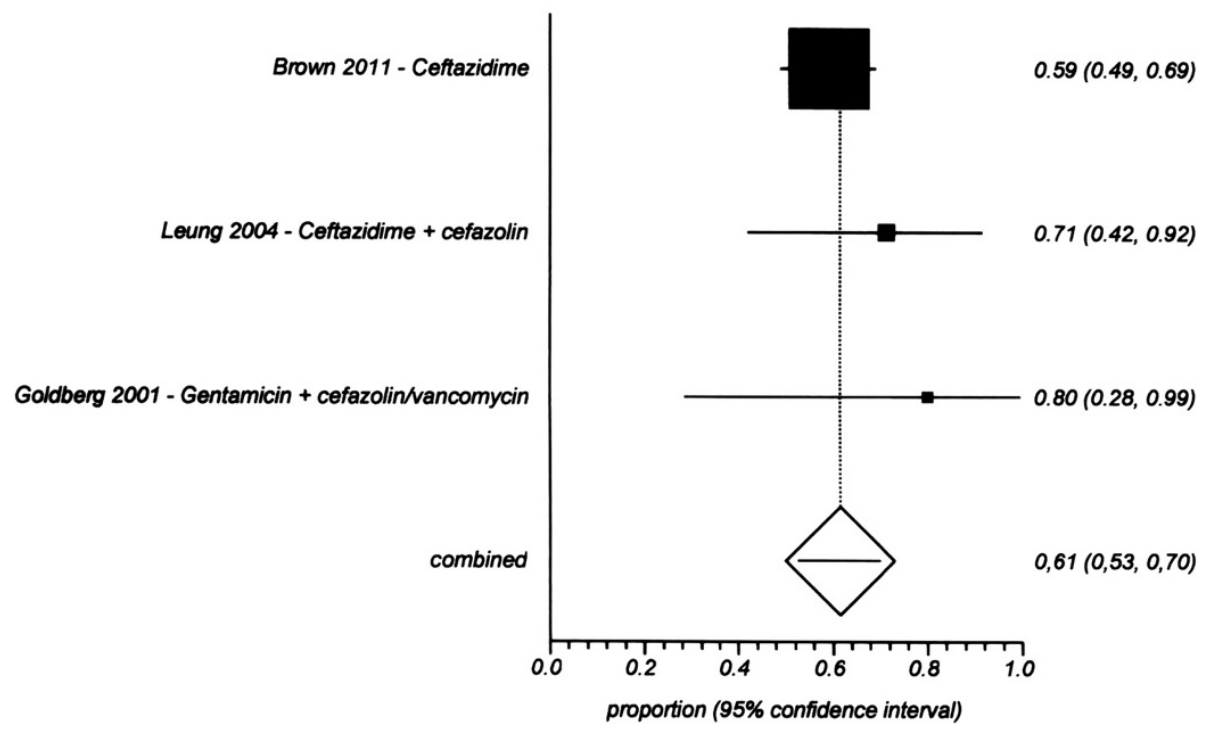

Figure 6 Proportional meta-analysis of studies of the resolution rate of ceftazidime treatment for gram-negative peritonitis. 


\section{Proportion meta-analysis plot [random effects]}

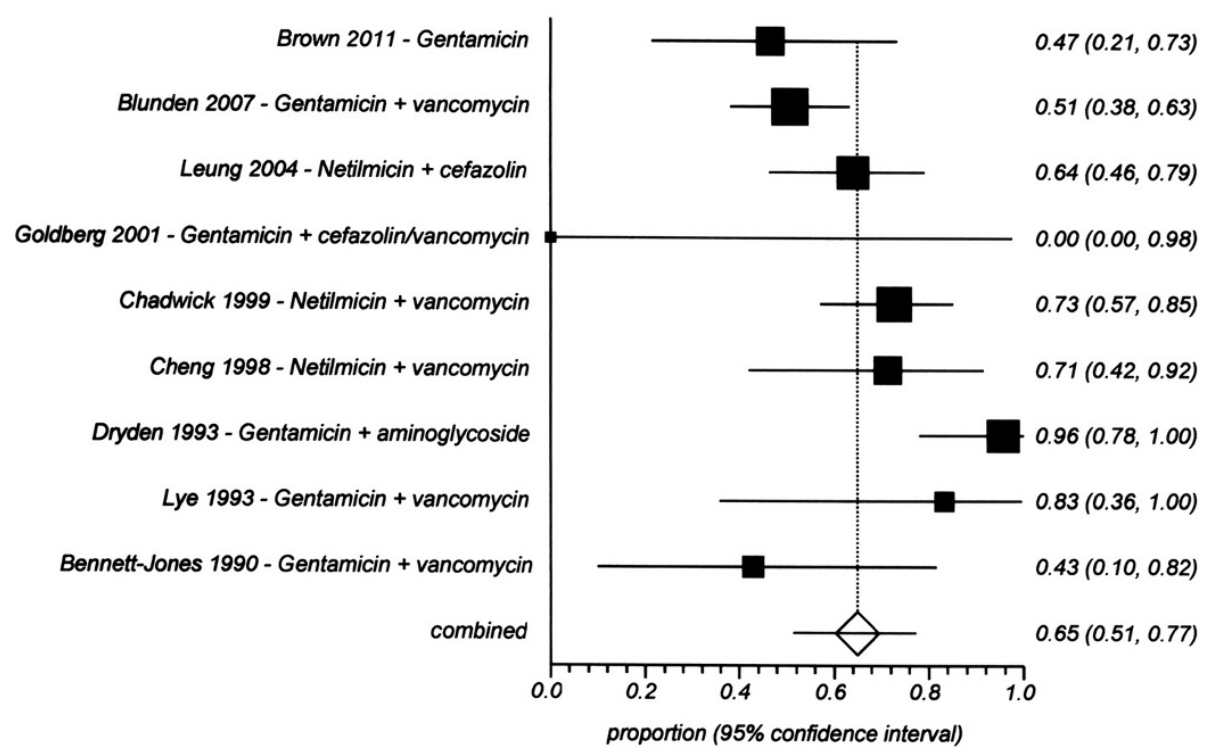

Figure 7 Proportional meta-analysis of studies of the resolution rate of aminoglycosides treatment for gram-negative peritonitis.

third generation cephalosporin compared with aminoglycosides. Bacterial resistance of Gram-negative bacilli, particularly Pseudomonas species, to commonly prescribed antimicrobials has been reported in recent years [101]; this may explain the superiority of the protocols employing ceftazidime. We found a low-resolution rate associated with regimens based on aminoglycosides for treatment of episodes caused by Gram-negatives. It was noticeable that papers of the decade 90 presenter higher resolution rate than those published after 2000, which could result of a temporal increase of bacterial resistance to these antibiotics. In agreement, low and decreasing susceptibility rate of Pseudomonas spp to gentamycin was reported in our center where only $40 \%$ of strains were susceptible in the same period period [101]. The set of these data suggests the bacterial resistance may explains the outcome of Gram-negative episodes treated with aminoglycosides.

The superiority observed with a glycopeptide plus ceftazidime must be carefully examined, because only 443 peritonitis episodes, in four case series [60-63] and only one RCT [59] were given this treatment. In addition, the comparisons among aminoglycosides, ceftazidime and fluoroquinolones used for the treatment of Gram-negative bacilli showed no differences in the resolution rates. Although the majority of these studies did not report the description of the bacterial resistance profile, differences in resistance may have influenced the outcome.

The present study confirms previous findings that showed no differences between vancomycin and first generation cephalosporins for the treatment of Grampositive cocci. However, it should be considered that an increase in methicillin-resistant coagulase negative staphylococci as causal agents of PD-related peritonitis has been reported by several authors [75,102], and that the results of this review may reflect conditions associated with the era or specific characteristics of each center.

This review has several limitations. The most important is the lower evidence level of case studies compared with the study designs of studies included in traditional systematic reviews. In addition, our analysis shows that there is significant heterogeneity in resolution rate. Finally, the studies differed considerably in their patient selection, baseline renal diseases, number of subjects, antibiotic administration routes, and other aspects. In conclusion, this review showed that the protocol of a glycopeptide plus ceftazidime could be a promising initial therapy in patients with PD-related peritonitis. This result should be carefully analyzed, and an emphasis should be placed on the necessity of monitoring the local microbiologic profile in each center regarding the initial therapeutic choice.

\section{Conclusion}

The association of a glycopeptide plus ceftazidime was superior to other regimens for initial treatment of PD peritonitis. This result should be carefully analyzed and does not exclude the necessity of monitoring the local microbiologic profile in each dialysis center to choice the initial therapeutic protocol. 


\section{Appendix}

Summary of the bibliographic search strategies for type of clinical situation and intervention of interest.

[(Primary Peritonitis) OR (Secondary Peritonitis) OR (Peritoneal Dialyses) OR (Peritoneal Dialyses) OR CAPD OR (Continuous Ambulatory Peritoneal Dialysis) OR APD OR (Automated Peritoneal Dialysis)] AND [(Anti Bacterial Agents) OR (Antibacterial Agents) OR (AntiMycobacterial Agents) OR (Anti Mycobacterial Agents) OR (Antimycobacterial Agents) OR Antibiotic OR Antibiotics OR (Bactericidal Agents) OR Bactericides).

\section{Competing interests}

The authors declare that they have no competing interests.

\section{Authors' contribution}

JVPD extracted the data. DGP helped extract the data. RED designed the research, carried out the analysis, and wrote the initial draft of the paper. PB has conceived the study and reviewed the draft of the paper. All authors read and approved the final manuscript.

\section{Acknowledgement}

This study was partially supported by the National Council for Scientific and Technological Development (CNPq) which provided an educational grant to JVD. We thank Marluci Betini, a librarian who helped us in acquisition of data.

Received: 24 June 2013 Accepted: 11 July 2014

Published: 18 August 2014

\section{References}

1. Davenport A: Peritonitis remains the major clinical complication of peritoneal dialysis: the London, UK, peritonitis audit 2002-2003. Perit Dial Int 2009, 29:297-302.

2. Keane WF, Everett ED, Fine RN, Golper TA, Vas S, Peterson PK, Gokal R, Matzke GR: Continuous ambulatory peritoneal dialysis (CAPD) peritonitis treatment recommendations: 1989 update. Perit Dial Int 1989, 9:247-256.

3. Keane WF, Everett ED, Golper TA, Gokal R, Halstenson C, Kawaguchi Y, Riella $M$, Vas S, Verbrugh HA: Peritoneal dialysis-related peritonitis treatment recommendations: 1993 update. Perit Dial Int 1993, 13:14-28.

4. Keane WF, Alexander SR, Bailie GR, Boeschoten E, Gokal R, Golper TA, Holmes CJ, Huang CC, Kawaguchi Y, Piraino B, Riella M, Schaefer F, Vas S: Peritoneal dialysis related peritonitis treatment recommendations: 1996 update. Perit Dial Int 1996, 16:557-573.

5. Keane WF, Bailie GR, Boeschoten E, Gokal R, Golper TA, Holmes CJ, Kawaguchi Y, Piraino B, Riella M, Vas S: Adult peritoneal dialysis-related peritonitis recommendations: 2000 update. Perit Dial Int 2000, 20:396-411.

6. Piraino B, Bailie GR, Bernardini J, Boeschoten E, Gupta A, Holmes C, Kuijper EJ, Li PK, Lye WC, Mujais S, Paterson DL, Fontan MP, Ramos A, Schaefer F, Uttley L: ISPD Ad Hoc Advisory Committee. Peritoneal dialysis-related infections recommendations: 2005 update. Perit Dial Int 2005, 25:107-131.

7. Li PK, Szeto CC, Piraino B, Bernardini J, Figueiredo AE, Gupta A, Johnson DW, Kuijper EJ, Lye WC, Salzer W, Schaefer F, Struijk DG: International Society for Peritoneal Dialysis. Peritoneal dialysis-related infections recommendations: 2010 update. Perit Dial Int 2010, 30:393-423.

8. Wiggins KJ, Johnson DW, Craig JC, Strippoli GF: Treatment of peritoneal dialysis-associated peritonitis: a systematic review of randomized controlled trials. Am J Kidney Dis 2007, 50:967-988.

9. Higgins JPT, Green S (Eds): Cochrane Handbook for Systematic Reviews of Interventions Version 5.1.0. [updated March 2011]. The Cochrane Collaboration; 2011. Available from http://handbook.cochrane.org.

10. Higgins JPT, Green S: Assessment of study quality. Cochrane Reviewers' Handbook 4.2.5. The Cochrane Library, Issue 3. 2005th edition. Chichester: John Wiley \& Sons, Ltd; 2005.

11. Higgins JP, Thompson SG, Deeks JJ, Altman DG: Measuring inconsistency in meta-analysis. BMJ 2003, 3:557-560.

12. Der Simonian R, Laird N: Meta-analysis in clinical trials. Control Clin Trials 1986, 7:177-188
13. El Dib R, Touma NJ, Kapoor A: Cryoablation versus Radiofrequency Ablation for the Treatment of Renal Cell Carcinoma: a meta-analysis of case series studies. BJU Int 2012, 110:510-516

14. El Dib R, Touma N, Kapoor A: A new approach to deal with the absence of clinical trials in systematic reviews: a meta-analysis of case series studies. New Zealand, Australia: 20th Cochrane Colloquium; 2012b.

15. Hyams PJ, Smithivas T, Matalon R, Katz L, Simberkoff MS, Rahal JJ Jr: The use of gentamicin in peritoneal dialysis. II. Microbiologic and clinical results. J Infect Dis 1971, 124(Suppl 124):84-89.

16. Gray HH, Goulding S, Eykyn SJ: Intraperitoneal vancomycin and ceftazidime in the treatment of CAPD peritonitis. Clin Nephrol 1985, 23:81-84.

17. Ryckelynck JP, Hurault de Ligny B, Vergnaud M, Dapogny C, Batho JM, Landru I: [Intraperitoneal ceftazime as treatment for peritonitis in patients on continuous ambulatory peritoneal dialysis]. Therapie 1987, 42:37-39.

18. Boeschoten EW, Kuijper EJ, Speelman P, Struijk DG, Krediet RT, Arisz L: Oral treatment of CAPD-peritonitis with ciprofloxacin. Adv Perit Dial 1990, 6:126-129.

19. Dratwa M, Glupczynski Y, Lameire N, Matthys D, Verschraegen G, Vaneechoutte M, Boelaert J, Schurgers M, Van Landuyt H, Verbeelen D, Lawers S: Treatment of gram-negative peritonitis with aztreonam in patients undergoing continuous ambulatory peritoneal dialysis. Rev Infect Dis 1991, 13(Suppl 7):S645-S647.

20. Dryden MS, Wing AJ, Phillips I: Low dose intraperitoneal ciprofloxacin for the treatment of peritonitis in patients receiving continuous ambulatory peritoneal dialysis (CAPD). J Antimicrob Chemother 1991, 28:131-139.

21. Nye KJ, Gibson SP, Nwosu AC, Manji MR, Robinson BHB, Hawkins JB: Single-Dose intraperitoneal vancomycin and oral ciprofloxacin for the treatment of peritonitis in CAPD patients: Preliminary report. Perit Dial Int 1993, 13:59-60.

22. Guerra EMM, D'Avila R, Rodrigues CIS, Cadaval RAM, Fernandes FA, Almeida FA: Tratamento de peritonites por bactérias Gram-negativas com aztreonam em pacientes submetidos a diálise peritoneal/Treatment of peritonitis by Gram-negative bacteria with aztreonam in patients submitted to peritoneal dialysis. Arq Bras Med 1994, 68:43-46.

23. Lui S-F, Cheng AB, Leung C-B, Wong K-C, Li PKT, Lai K-N: Imipenem/cilastatin sodium in the treatment of continuous ambulatory peritoneal dialysis-associated peritonitis. Am J Nephrol 1994, 14:182-186.

24. Brulez HF, Moncasi EP, Posthuma N, Choy K, ter Wee PM: The efficacy of intraperitoneally administered gentamicin and rifampin as initial treatment of peritoneal dialysis-related peritonitis. Adv Perit Dial 1995, 11:182-186.

25. Goffin E, Pouthier D, Vandercam B, Gigi J: IV vancomycin-oral ciprofloxacin: a safe and efficient therapeutic protocol for CAPD peritonitis (preliminary report). Perit Dial Int 1996, 6:174-177.

26. Shemin D, Maaz D: Gram-negative peritonitis in peritoneal dialysis: Improved outcome with intraperitoneal ceftazidime. Perit Dial Int 1996, 16:637-640.

27. Szeto CC, Chow VC, Chow KM, Lai RW, Chung KY, Leung CB, Kwan BC, Li PK Enterobacteriaceae peritonitis complicating peritoneal dialysis: a review of 210 consecutive cases. Kidney Int 2006, 69:1245-1252.

28. Yorioka N, Taniguchi Y, Ito T, Katsutani M, Amimoto D, Masaki T, Nishida Y, Kushihata S, Oda H, Yamakido M: Vancomycin therapy for treatment of peritonitis in outpatients on peritoneal dialysis. Hiroshima J Med Sci 1998, 47:105-107.

29. Lévesque R, Lemieux C, Laverdiere M, Pichette V: Treatment of gram-positive peritonitis in peritoneal dialysis patients:cefazolin or vancomycin? Perit Dial Int 2003, 23:599-601.

30. Kobayashi K, Nakamoto H, Okada S, Hoshitani K, Uchida K, Arima H, Shoda J, Takane Y, Ikeda N, Sugahara S, Okada H, Suzuki H: Efficacy and safety of meropenem plus tobramycin followed by meropenem plus vancomycin for treating peritonitis in patients on continuous ambulatory peritoneal dialysis. Adv Perit Dial 2006, 22:65-68.

31. Leppänen H, Metsärinne KP, Nikoskelainen J, Tertti R: Three-year analysis of microbial aetiology and antimicrobial susceptibilities of PD peritonitis. Scand J Infect Dis 2006, 38:645-649.

32. Shukla A, Abreu Z, Bargman JM: Streptococcal PD peritonitis-a 10-year review of one centre's experience. Nephrol Dial Transplant 2006, 21:3545-3549.

33. Brown F, Liu WJ, Kotsanas D, Korman TM, Atkins RC: A quarter of a century of adult peritoneal dialysis-related peritonitis at an Australian medical center. Perit Dial Int 2007, 27:565-574. 
34. Lima RCS, Barreira A, Cardoso FL, Lima MHS, Leite M Jr: Ciprofloxacin and cefazolin as a combination for empirical initial therapy of peritoneal dialysis-related peritonitis: Five-year follow-up. Perit Dial Int 2007, 27:56-60.

35. Kabat-Koperska J, Golembiewska E, Ciechanowski K: Peritoneal dialysis-related peritonitis in the years 2005-2007 among patients of the Peritoneal Dialysis Clinic of the Department of Nephrology, Transplantology and Internal Medicine, Pomeranian Medical University in Szczecin. Pol Arch Med Wewn 2008, 118:694-699.

36. Santoianni JE, Predari SC, Veron D, Zucchini A, De Paulis AN: A 15 year-review of peritoneal dialysis-related peritonitis: Microbiological trends and patterns of infection in a teaching hospital in Argentina. Rev Argent Microbio/ 2008 40:17-23.

37. Fontán MP, Cambre HD, Rodríguez-Carmona A, Muñiz AL, Falcón TG: Treatment of peritoneal dialysis-related peritonitis with ciprofloxacin monotherapy: clinical outcomes and bacterial susceptibility over two decades. Perit Dial Int 2009, 29:310-318.

38. O'Shea S, Hawley CM, McDonald SP, Brown FG, Rosman JB, Wiggins KJ, Bannister KM, Johnson DW: Streptococcal peritonitis in Australian peritoneal dialysis patients: predictors, treatment and outcomes in 287 cases. BMC Nephrol 2009, 26:10-19.

39. Szeto CC, Kwan BC, Chow KM, Law MC, Pang WF, Chung KY, Leung CB, Li PK: Recurrent and relapsing peritonitis: causative organisms and response to treatment. Am J Kidney Dis 2009, 54:702-710.

40. Barraclough K, Hawley CM, McDonald SP, Brown FG, Rosman JB, Wiggins KJ, Bannister KM, Johnson DW: Polymicrobial peritonitis in peritoneal dialysis patients in Australia:predictors, treatment, and outcomes. Am J Kidney Dis 2010, 55:121-131.

41. Edey M, Hawley CM, McDonald SP, Brown FG, Rosman JB, Wiggins KJ, Bannister KM, Johnson DW: Enterococcal peritonitis in Australian peritoneal dialysis patients: predictors, treatment and outcomes in 116 cases. Nephrol Dial Transplant 2010, 25:1272-1278.

42. Fahim M, Hawley CM, McDonald SP, Brown FG, Rosman JB, Wiggins KJ Bannister KM, Johnson DW: Culture-negative peritonitis in peritoneal dialysis patients in Australia:predictors, treatment, and outcomes in 435 cases. Am J Kidney Dis 2010, 55:690-697.

43. Fahim M, Hawley CM, McDonald SP, Brown FG, Rosman JB, Wiggins KJ, Bannister KM, Johnson DW: Coagulase-negative staphylococcal peritonitis in Australian peritoneal dialysis patients: predictors, treatment and outcomes in 936 cases. Nephrol Dial Transplant 2010, 25:3386-3392.

44. Govindarajulu S, Hawley CM, McDonald SP, Brown FG, Rosman JB, Wiggins KJ, Bannister KM, Johnson DW: Staphylococcus aureus peritonitis in Australian peritoneal dialysis patients:predictors, treatment, and outcomes in 503 cases. Perit Dial Int 2010, 30:311-319.

45. Heywood A, Bargman JM: Coagulase-negative staphylococcal peritonitis: outcomes of cephalosporin-resistant strains. Adv Perit Dial 2010, 26:34-36.

46. Kofteridis DP, Valachis A, Perakis K, Maraki S, Daphnis E, Samonis G: Peritoneal dialysis-associated peritonitis: clinical features and predictors of outcome. Int J Infect Dis 2010, 14:e489-e493.

47. Noone D, Edwards L, Boyle S, Kinlough M, Riordan M, Awan A: Low rate of peritonitis in children on peritoneal dialysis, 5 year review from a single-centre. Pediatr Nephrol 2010, 25:1834.

48. Ghali JR, Bannister KM, Brown FG, Rosman JB, Wiggins KJ, Johnson DW, McDonald SP: Microbiology and outcomes of peritonitis in Australian peritoneal dialysis patients. Perit Dial Int 2011, 31:651-662.

49. Peres LAB, Matsuo T, Ann HK, Camargo MTA, Rohde NRS, Uscocovich VSM, Litchteneker K, Frederico SAM: Peritonites em diálise peritoneal ambulatorial contínua/Peritonitis in continuous ambulatory peritoneal dialysis. Rev Soc Bras Clín Méd 2011, 9:5.

50. Szeto CC, Kwan BC, Chow KM, Lau MF, Law MC, Chung KY, Leung CB, Li PK: Repeat peritonitis in peritoneal dialysis: Retrospective review of 181 consecutive cases. Clin J Am Soc Nephrol 2011, 6:827-833.

51. Yip T, Tse KC, Ng F, Hung I, Lam MF, Tang S, Lui SL, Lai KN, Chan TM, Lo WK. Clinical course and outcomes of single-organism Enterococcus peritonitis inperitoneal dialysis patients. Perit Dial Int 2011, 31:522-528.

52. Yap DYH, To KKW, Yip TPS, Lui SL, Chan TM, Lai KN, Lo WK: Streptococcus bovis peritonitis complicating peritoneal dialysis-a review of 10 years' experience. Perit Dials Int 2012, 32:55-59.

53. Searle M, Raman GV: Oral treatment of peritonitis complicating continuous ambulatory peritoneal dialysis. Clin Nephrol 1985, 23:241-244.

54. Al-Wali W, Baillod RA, Brumfitt W, Hamilton-Miller JMT: Teicoplanin in the treatment of peritonitis in patients receiving continuous ambulatory peritoneal dialysis: A comparative trial against vancomycin. Int J Antimicrob Agents 1992, 1:S1-S6.

55. Lye WC, Lee EJ, van der Straaten J: Intraperitoneal vancomycin/oral pefloxacin versus intraperitoneal vancomycin/gentamicin in the treatment of continuous ambulatory peritoneal dialysis peritonitis. Perit Dial Int 1993, 13:S348-S350.

56. Fijter CW, ter Wee PM, Oe LP, Verbrugh HÁ: Intraperitoneal ciprofloxacin and rifampicin versus cephradine as initial treatment of (C)APD-related peritonitis: a prospective randomized multicenter comparison (CIPPER trial). Perit Dial Int 2001, 21:480-486.

57. Leung CB, Szeto CC, Chow KM, Kwan BC, Wang AY, Lui SF, Li PK: Cefazolin plus ceftazidime versus imipenem/cilastatin monotherapy for treatment of CAPD peritonitis-a randomized controlled trial. Perit Dial Int 2004, 24:440-446.

58. Khairullah Q, Provenzano R, Tayeb J, Ahmad A, Balakrishnan R, Morrison L: Comparison of vancomycin versus cefazolin as initial therapy for peritonitis in peritoneal dialysis patients. Perit Dial Int 2002, 22:339-344.

59. Ludlam HA, Price TN, Berry AJ, Phillips I: Laboratory diagnosis of peritonitis in patients on continuous ambulatory peritoneal dialysis. J Clin Microbiol 1988, 26:1757-1762.

60. Beaman M, Solaro L, McGonigle RJ, Michael J, Adu D: Vancomycin and ceftazidime in the treatment of CAPD peritonitis. Nephron 1989, 51:51-55.

61. Gucek A, Bren AF, Hergouth V, Lindic J: Cefazolin and netilmycin versus vancomycin and ceftazidime in the treatment of CAPD peritonitis. Adv Perit Dial 1997, 13:218-220.

62. Blunden M, Zeitlin D, Ashman N, Fan SL-S: Single UK centre experience on the treatment of PD peritonitis - Antibiotic levels and outcomes. Nephrol Dial Transplant 2007, 22:1714-1719.

63. Lartundo JAQ, Palomar R, Dominguez-Diez A, Salas C, Ruiz-Criado J, Rodrigo E, Martinez De Francisco AL, Arias M: Microbiological profile of peritoneal dialysis peritonitis and predictors of hospitalization. Adv Perit Dial 2011, 27:38-42.

64. Chan MK, Cheng IK, Ng WS: A randomized prospective trial of three different regimens of treatment of peritonitis in patients on continuous ambulatory peritoneal dialysis. Am J Kidney Dis 1990, 15:155-159.

65. Weber J, Kuhlmann U: Intraperitoneal cefazolin and gentamicin in the management of CAPD-related peritonitis. Contrib Nephrol 1991, 89:108.

66. Lupo A, Rugiu C, Bernich P, Laudon A, Marcantoni C, Mosconi G, Cantaluppi MC, Maschio G: A prospective randomized trial of two antibiotic regimens in the treatment of peritonitis in CAPD patients: teicoplanin plus tobramycin versus cephalotin plus tobramycin. J Antimicrob Chemother 1997, 729-732.

67. Vas S, Bargman J, Oreopoulos D: Treatment in PD patients of peritonitis caused by gram-positive organisms with single daily dose of antibiotics. Perit Dial Int 1997, 17:91-94.

68. Goldberg L, Clemenger M, Azadian B, Brown EA: Initial treatment of peritoneal dialysis peritonitis without vancomycin with a once-daily cefazolin-based regimen. Am J Kidney Dis 2001, 37:49-55.

69. Silva MM, Pecoits-Filho R, Rocha CS, Stinghen AE, Pachaly MA, Nascimento MM, Campos RP, Sauthier S, Fuerbringer R, Riella MC: The recommendations from the International Society for Peritoneal Dialysis for Peritonitis Treatment: a single-center historical comparison. Adv Perit Dial 2004, 20:74-77.

70. Toussaint N, Mullins K, Snider J, Murphy B, Langham R, Gock H: Efficacy of a non-vancomycin-based peritoneal dialysis peritonitis protocol. Nephrology (Carlton) 2005, 10:142-146.

71. Chen KH, Chang CT, Weng SM, Yu CC, Fang JT, Huang JY, Yang CW, Hung CC: Culture-negative peritonitis: a fifteen-year review. Ren Fail 2007 29:177-181.

72. Barretti P, Montelli AC, Batalha JE, Caramori JC, Cunha Mde L: The role of virulence factors in the outcome of staphylococcal peritonitis in CAPD patients. BMC Infect Dis 2009, 9:212

73. Lee CC, Sun CY, Chang KC, Wu MS: Positive dialysate gram stain predicts outcome of empirical antibiotic therapy for peritoneal dialysis-associated peritonitis. Ther Apher Dial 2010, 14:201-218.

74. Huang S-T, Chuang Y-W, Cheng C-H, Wu M-J, Chen C-H, Yu T-M, Shu K-H: Evolution of microbiological trends and treatment outcomes in peritoneal dialysis-related peritonitis. Clin Nephrol 2011, 75:416-425.

75. Oliveira LG, Luengo J, Caramori JC, Montelli AC, Cunha MD, Barretti P: Peritonitis in recent years: clinical findings and predictors of treatmentresponse of 170 episodes at a single Brazilian center. Int Urol Nephrol 2012, 44:1529-1537. 
76. Bennett-Jones DN, Russell GI, Barrett A: A comparison between oral ciprofloxacin and intra-peritoneal vancomycin and gentamicin in the treatment of CAPD peritonitis. J Antimicrob Chemother 1990, 26:F73-F76.

77. Friedland JS, Iveson TJ, Fraise AP, Winearls CG, Selkon JB, Oliver DO: A comparison between intraperitoneal ciprofloxacin and intraperitoneal vancomycin and gentamicin in the treatment of peritonitis associated with continuous ambulatory peritoneal dialysis (CAPD). J Antimicrob Chemother 1990, 26:F77-F81.

78. Tapson JS, Orr KE, George JC, Stansfield E, Bint AJ, Ward MK: A comparison between oral ciprofloxacin and intraperitoneal vancomycin and netilmicin in CAPD peritonitis. J Antimicrob Chemother 1990, 26:F63-F71.

79. Merchant MR, Anwar N, Were A, Uttley L, Tooth JA, Gokal R: Imipenem versus netilmicin and vancomycin in the treatment of CAPD peritonitis. Adv Perit Dial 1992, 8:234-247.

80. Were AJ, Marsden A, Tooth A, Ramsden R, Mistry CD, Gokal R: Netilmycin and vancomycin in the treatment of peritonitis in CAPD patients. Clin Nephrol 1992, 37:209-213.

81. Anwar N, Merchant M, Were T, Tooth A, Uttley L, Gokal R: A prospective, randomized study of the comparative safety and efficacy of intraperitoneal imipenem versus vancomycin and netilmicin in the treatment of peritonitis on CAPD. Perit Dial Int 1995, 15:167-171.

82. Guest SS, Erickson L: Combination therapy involving ciprofloxacin for peritonitis. Perit Dial Int 1996, 16:316-318.

83. Lai MN, Kao MT, Chen CC, Cheung SY, Chung WK: Intraperitoneal once-daily dose of cefazolin and gentamicin for treating CAPD peritonitis. Perit Dial Int 1997, 17:87-89.

84. Bowley JA, Pickering SJ, Scantlebury AJ, Ackrill P, Jones DM: Intraperitoneal teicoplanin in the treatment of peritonitis associated with continuous ambulatory peritoneal dialysis. J Antimicrob Chemother 1988, 21:A133-A139.

85. Cheng IK, Fang GX, Chau PY, Chan TM, Tong KL, Wong AK, Li CS, Lo WK, Cheung KO, Kumana CR: A randomized prospective comparison of oral levofloxacin plus intraperitoneal (IP) vancomycin and IP netromycin plus IP vancomycin as primary treatment of peritonitis complicating CAPD. Perit Dial Int 1998, 18:371-375.

86. Wong KM, Chan YH, Cheung CY, Wai LC, Choi KS, Leung SH, Leung J, Ka Foon C, Tsang DNC, Li CS: Cefepime versus vancomycin plus netilmicin therapy for continuous ambulatory peritoneal dialysis-associated peritonitis. Am. J. Kidney Dis 2001, 38:127-131.

87. Vargemezis $V$, Pasadakis $P$, Thodis $H$, Coucudis $P$, Peihaberis $P$, Jafer $H$, Jara F, Kartali S: Vancomycin therapy for gram-positive peritonitis in patients on CAPD. Adv Perit Dial 1989, 5:128-129.

88. Flanigan MJ, Lim VS: Initial treatment of dialysis associated peritonitis: a controlled trial of vancomycin versus cefazolin. Perit Dial Int 1991, $11: 31-37$

89. Bailie GR, Haqqie SS, Eisele G, Gorman T, Low CL: Effectiveness of once-weekly vancomycin and once-daily gentamicin, intraperitoneally, for CAPD peritonitis. Perit Dial Int 1995, 15:269-271.

90. Chadwick DH, Agarwal S, Vora BJ, Hair M, McKewan A, Gokal R: Outcome of peritonitis treated with intraperitoneal (i.p.) weekly vancomycin and i.p. daily netilmicin. J Nephrol 1999, 12:318-321.

91. Li PK, Ip M, Law MC, Szeto CC, Leung CB, Wong TY, Ho KK, Wang AY, Lui SF, Yu AW, Lyon DJ, Cheng AF, Lai KN: Use of intraperitoneal cefepime as monotherapy in treatment of CAPD peritonitis. Perit Dial Int 2000, 20:232-234.

92. Goffin E, Herbiet L, Pouthier D, Pochet JM, Lafontaine JJ, Christophe JL, Gigi J, Vandercam B: Vancomycin and ciprofloxacin: systemic antibiotic administration for peritoneal dialysis-associated peritonitis. Perit Dial Int 2004, 24:433-439.

93. Szeto CC, Kwan BC, Chow KM, Lau MF, Law MC, Chung KY, Leung CB, Li PK: Coagulase negative staphylococcal peritonitis in peritoneal dialysis patients: review of 232 consecutive cases. Clin J Am Soc Nephrol 2008, 3:91-97.

94. Percival A, Cohen SL: The treatment of peritoneal infections in patients on peritoneal dialysis. Postgrad Med J 1967, 43(Suppl):160-165.

95. Ludlam HA, Barton I, White L, McMullin C, King A, Phillips I: Intraperitoneal ciprofloxacin for the treatment of peritonitis in patients receiving continuous ambulatory peritoneal dialysis (CAPD). J Antimicrob Chemother 1990, 25:843-851.

96. Cheng IK, Chan CY, Wong WT: A randomised prospective comparison of oral ofloxacin and intraperitoneal vancomycin plus aztreonam in the treatment of bacterial peritonitis complicating continuous ambulatory peritoneal dialysis (CAPD). Perit Dial Int 1991, 11:27-30.

97. Dryden M, Eykyn SJ: Short-course gentamicin in gram-negative CAPD peritonitis. Lancet 1993, 341(8843):8497.

98. Brown MC, Simpson K, Kerssens JJ: Mactier R.A Peritoneal dialysis-associated peritonitis rates and outcomes in a national cohort are not improving in the post-millennium (2000-2007). Perit Dial Int 2011, 31:639-650

99. Ballinger AE, Palmer SC, Wiggins KJ, Craig JC, Johnson DW, Cross NB, Strippoli GFM: Treatment for peritoneal dialysis-associated peritonitis. Cochrane Database Syst Rev 2014, 26;4:CD005284. doi: 10.1002/14651858.

100. Milikin SMG, Keane WF: Antimicrobial treatment of peritonitis associated with continuous ambulatory peritoneal dialysis. Perit Dial Int 1991, 11:252-260.

101. Barretti P, Pereira D, Brasil MA, de Lourdes CM, Caramori J, Montelli A: Evolution of gram-negative bacilli susceptibility in peritoneal dialysis-related peritonitis in Brazil: a single center's experience over nine years. Perit Dial Int 2009, 29:230-233.

102. Kim DK, Yoo TH, Ryu DR, Xu ZG, Kim HJ, Choi KH, Lee HY, Han DS, Kang SW: Changes in causative organisms and their antimicrobial susceptibilities in CAPD peritonitis: a single center's experience over one decade. Perit Dial Int 2004, 24:424-432.

\section{doi:10.1186/1471-2334-14-445}

Cite this article as: Barretti et al:: Efficacy of antibiotic therapy for peritoneal dialysis-associated peritonitis: a proportional meta-analysis. BMC Infectious Diseases 2014 14:445.

\section{Submit your next manuscript to BioMed Central and take full advantage of:}

- Convenient online submission

- Thorough peer review

- No space constraints or color figure charges

- Immediate publication on acceptance

- Inclusion in PubMed, CAS, Scopus and Google Scholar

- Research which is freely available for redistribution 